\title{
OBSERVATION ON BED VARIATION IN A MEANDERING LIKE FLUME WITH RIVER TRAINING STRUCTURES
}

\author{
Sanjay GIRI ${ }^{1}$ and Yasuyuki SHIMIZU 2 \\ ${ }^{1}$ Student member of JSCE, PhD candidate, Dept. of Hydroscience \& Environmental Engineering, Hokkaido \\ University (Kita 13, Nishi 8, Sapporo 060, Japan) \\ ${ }^{2}$ Member of JSCE, D. Eng., Associate Professor, Dept. of Hydroscience \& Environmental Engineering, Hokkaido \\ University (Kita 13, Nishi 8, Sapporo 060, Japan)
}

\begin{abstract}
An explorative physical model study reported herein was conducted in a mildly meandering like laboratory flume with spurs as river training structure in order to observe the bed variation near the spurs as well as in further down stream region. Study was performed under the clear water condition using two different grain sizes $(0.28 \mathrm{~mm} \mathrm{\&} 1.2 \mathrm{~mm})$. In this study, temporal bed variation near series of spurs in different part of bend was determined simultaneously using long run experiments under various hydraulic and experimental conditions. Moreover, bed form induced by spurs in further down-stream region was also observed. It has been shown that temporal variation of relative scour depth can be generalized using a similarity number referred to as Strouhal number. An attempt was made to observe vegetation impact on local bed evolution having planted living vegetation (alfalfa) near the spur region under laboratory condition.
\end{abstract}

Key Words: structure-induced bed-forms, clear water scour, temporal development of scour, vegetation, alfalfa

\section{INTRODUCTION}

River training structures are widely implemented for various purposes such as bank protection, navigation \& habitat improvements and other river control works. On the contrary, such structure may produce significant impact on river environment associated with changeable hydraulic condition \& non-equilibrium sediment transport. In addition, bed entrainment near structure may cause failure of structure itself. Consequently, structure-induced bed evolution should be considered as a complex problem that needs a comprehensive analysis which is thought to be possible observing the process physically. This study has made a basic attempt to identify the structure-induced bed-forms as well as temporal variation of scour holes near series of spurs. In addition, an attempt was made to assess the impact of vegetation on this process having planted living vegetation (alfalfa). These observations were made to evaluate qualitatively the reduction of bed -load entrainment near the vicinity of spurs not just due to the drag on stem but due to the root strength as well. Qualitative evaluation of this study shows that the vegetation has significant impact on sediment entrainment.

Of most previous studies ${ }^{1)}$ was confined within the definition of local bed evolution near a single spur $^{2), 3), 4)}$ based on equilibrium scour depth. Most of them were conducted for clear water condition for which just quasi-equilibrium condition can be gained. Consequently, the time development of scour is of significance to define structure-induced bed evolution for design purpose. On the other hand, design criteria based on local bed evolution near single structure may not be efficient and economical for designing the series of training structures.

In this study, temporal bed variation near the series of spurs was evaluated simultaneously. Moreover, bed-form in further down-stream region was observed as well under various hydraulic and experimental conditions. Structure-induced bed forms were observed for fine-grained sand bed with transitional flow.

Experimental evidences have revealed various aspects of structure-induced impact not only locally but also on general bed migration towards down-stream depending particularly on flow intensity, and influence of channel plan form as well as vegetation impact on this process. These observations may be of use to improve understanding of such a sophisticated phenomenon.

A general trend of temporal variation of relative scour depth was defined and verified using results of 
other significant experiments having long run \& wide range of experimental condition as well. It has been shown that the temporal bed evolution normalized by quasi-equilibrium state can be generalized extensively even for bridge structures.

\section{EXPERIMENTAL CONFIGURATION}

Study was carried out in a physical model constructed in Laboratory of Hydro-science \& Environmental Department of Hokkaido University. A $28 \mathrm{~m}$ long and $1 \mathrm{~m}$ wide flume was constructed with upstream and downstream straight reaches of $9.8 \mathrm{~m} \& 10.5 \mathrm{~m}$ respectively. Meandering like reach with $7.7 \mathrm{~m}$ wave length consists of three consecutive $\&$ opposite bends (Fig.1) having constant arc angles of $40^{\circ}, 80^{\circ} \& 40^{\circ}$ respectively. Flume was constructed on a $30 \mathrm{~m}$ by $2.5 \mathrm{~m}$ plat-form having electrical motor mechanism for slope regulation. The meandering like shape was adopted according as weakly developed meandering form with short bends. Similarly, bend radius to channel width ratio, namely 3 , was adopted according as most common bend migration ratio ${ }^{5)}$. Experimental condition was considered as characteristics of Lowland River with sub-critical flow. The experimental cases are summarized in Table1. Study was conducted for non-submerged condition as more often and critical in natural case. Protrusion length of spurs $(L) \&$ allocations have been summarized in Table 1 as well. A couple of experiments were conducted with vegetation, for which seeds of alfalfa were grown near spur region. Growth of alfalfa was found to be about $3.5 \mathrm{~cm}$ in one week. Length of root was $3 \mathrm{~cm}$.

\section{DETERMINATION OF CRITICAL \& THRESHOLD VELOCITIES}

Critical shear velocity for sand particle $\left(U_{* 0}\right)$ is calculated using following Criterial relationship, which is valid for all flow regions ${ }^{6)}$ :

$$
\begin{aligned}
\mathrm{Re}_{*} & =a A r_{d}{ }^{n} \\
\mathrm{Re}_{*} & =\frac{U_{*_{0}} d}{v} \\
A r_{d} & =\left(\frac{\rho_{1}-\rho}{\rho}\right) \frac{g d^{3}}{v^{2}}
\end{aligned}
$$

Where, $\mathrm{Re}_{*}$ - Grain-size Reynolds number; $A r_{d}$ Archimedean number; $d$ - particle diameter; $\rho \& \rho_{1}$ - Density of water \& sediment; $v$ Kinematic viscosity; $a \& n$ - Parameters associated with particle shape \& flow region. For the case with $d=0.28 \mathrm{~mm}$, i.e. transitional regime with $2.4 \times 10^{2}$ $\leq A_{r d}<1.6 \times\left(10^{4}-10^{5}\right) ; \quad a=0.314, n=0.432$;

For $d=1.20 \mathrm{~mm}$, i.e. rough turbulent regime with $A r_{d}>1.6 \times\left(10^{4}-10^{5}\right), a=0.162, n=0.5$

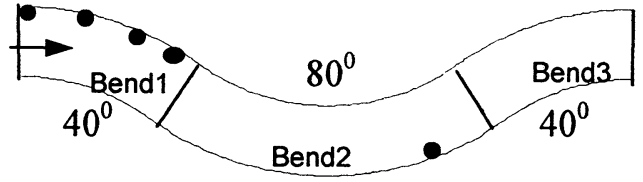

Fig.1 Location of spurs for different cases

Consequently, $U_{*_{0}}$ for $0.28 \mathrm{~mm}$ and $1.20 \mathrm{~mm}$ sand was calculated from (3.1)-(3.3) \& obtained the values of $1.4 \mathrm{~cm} / \mathrm{sec} \& 2.3 \mathrm{~cm} / \mathrm{sec}$ respectively.

Threshold velocity (referred to as non-eroding velocity in Russian literatures) was calculated using following relationship valid for channel with rectangle shape having different roughness of wall and bed ${ }^{6}$ :

$$
U_{t}=U_{* 0} \sqrt{\frac{2 t}{\lambda_{b}}}
$$

Where, $t$ - correction parameter for resistance, produced by channel wall in case of $B / h<10$;

( $t=1$ is adopted in our calculations);

$U_{t}$ - Threshold velocity;

$U_{*_{0}}$ - Critical shear velocity for sand particle;

$\lambda_{b}$ - Friction factor of channel bed $\left(\lambda_{b}=\lambda\right)$;

$\lambda$ can be calculated using following relations:

For rough turbulent regime $(\mathrm{d}=1.2 \mathrm{~mm})$ :

$\frac{1}{\sqrt{\lambda}}=4 \log \frac{R}{k}+4.25$

For transitional regime $(\mathrm{d}=0.28 \mathrm{~mm})$ :

$\frac{1}{\sqrt{\lambda}}=4 \log \frac{R}{k}-1.4 \log A_{r k}+11.28$

Where, $\lambda$ - friction factor; $R$ - hydraulic radius $(R \approx h$ for $B / h>10$; $k=f(d)$-equivalent roughness;

For uniform grain size ${ }^{7}$,

$k=\beta d^{0.75}$, where, $\beta=1.4(k \& d$ in $\mathrm{mm})$;

$A_{r k}$ - Archimedean number, in which $d$ should be replaced with $k$ in (3.3).

Since threshold velocity is related with dynamic velocity as (3.4), hence having defined friction factor, threshold velocity can be calculated for each case. Similarly, shear velocity can also be calculated using the same expression as (3.4) replacing $U_{t}$ to $U_{0}$ (approach velocity) for each case. Calculation results have been presented in Table 1. Calculated and observed velocity of incipient motion was found with well agreement.

\section{OBSERVATION ON GENERAL BED FORM \& LOCAL BED EVOLUTION NEAR SPURS}

In all experimental runs with $0.28 \mathrm{~mm}$ sand, sand wave in form of dunes and ripples was seen to have migrated towards downstream region gradually from the tip of the spurs with deep scouring. Sand wave migration pattern in the bend reach was found to be distinctive depending upon the flow condition and constriction ratio. Magnitude of these 
Table 1 Flow \& experimental conditions

\begin{tabular}{|c|c|c|c|c|c|c|c|c|}
\hline $\begin{array}{l}\text { Case } \\
\text { No. }\end{array}$ & $\begin{array}{l}h, \\
\mathrm{~cm}\end{array}$ & $\begin{array}{c}U_{0} \\
\mathrm{~cm} / \mathrm{s}\end{array}$ & $\begin{array}{l}L, \\
\mathrm{~cm}\end{array}$ & $\begin{array}{c}T, \\
\mathrm{hrs}\end{array}$ & $\begin{array}{c}\text { Froude no. } \\
\text { Fr }\end{array}$ & $\begin{array}{c}U_{*} \\
\mathrm{Cm} / \mathrm{s}\end{array}$ & $\begin{array}{c}U_{0} U_{t} \\
\left(U_{*} / U_{*_{0}}\right)\end{array}$ & $\begin{array}{l}\text { Qty of spurs } \\
\text { (Location) }\end{array}$ \\
\hline \multicolumn{9}{|c|}{ Medium grain-size, $d=0.28 \mathrm{~mm}$} \\
\hline 1 & 9.8 & 19.90 & 25 & 26.0 & 0.203 & 1.22 & 0.87 & 1 (in straight reach) \\
\hline 2 & 9.8 & 19.90 & 25 & 26.0 & 0.203 & 1.22 & 0.87 & 1 (in bend- $1^{0}$ ) \\
\hline 3 & 9.8 & 19.90 & 25 & 28.0 & 0.203 & 1.22 & 0.87 & $2\left(1^{0} \& 15^{0}\right)$ \\
\hline 4 & 9.8 & 19.90 & 25 & 28.6 & 0.203 & 1.22 & 0.87 & $3\left(1^{0}, 15^{0} \& 29^{0}\right)$ \\
\hline 5 & 9.8 & 19.90 & 19 & 28.3 & 0.203 & 1.22 & 0.87 & $3\left(1^{0}, 15^{0} \& 29^{0}\right)$ \\
\hline 6 & 9.8 & 19.90 & 13 & 28.0 & 0.203 & 1.22 & 0.87 & $3\left(1^{0}, 15^{0} \& 29^{0}\right)$ \\
\hline 7 & 8.2 & 23.78 & 19 & 8.0 & 0.265 & 1.5 & 1.07 & $3\left(1^{0}, 15^{0} \& 29^{0}\right)$ \\
\hline 8 & 8.2 & 23.78 & 13 & 8.75 & 0.265 & 1.5 & 1.07 & $3\left(1^{0}, 15^{0} \& 29^{0}\right)$ \\
\hline 9 & 7.0 & 20.86 & 19 & 8.5 & 0.252 & 1.35 & 0.96 & $3\left(1^{0}, 15^{0} \& 29^{0}\right)$ \\
\hline 10 & 7.0 & 20.86 & 13 & 8.5 & 0.252 & 1.35 & 0.96 & $3\left(1^{0}, 15^{0} \& 29^{0}\right)$ \\
\hline 11 & 8.8 & 22.16 & 13 & 25.0 & 0.239 & 1.40 & 1.00 & $3\left(1^{0}, 7^{0} \& 13^{0}\right)$ \\
\hline 12 & 8.0 & 18.25 & 25 & 12.5 & 0.206 & 1.15 & 0.82 & $2\left(1^{0} \& 32^{0}\right)$ \\
\hline 13 & 8.8 & 22.16 & 25 & 6.0 & 0.239 & 1.40 & 1.00 & $2\left(1^{0} \& 32^{0}\right)$ \\
\hline 14 & 8.8 & 22.16 & 19 & 28.0 & 0.239 & 1.40 & 1.00 & $2\left(1^{0} \& 24^{0}\right)$ \\
\hline \multicolumn{9}{|c|}{ Medium grain-size, $d=1.20 \mathrm{~mm}$} \\
\hline 15 & 8.8 & 22.16 & 25 & 10 & 0.239 & 1.40 & 0.61 & $2\left(1^{0} \& 32^{0}\right)$ \\
\hline 16 & 8.0 & 18.25 & 25 & 6 & 0.206 & 1.20 & 0.51 & $2\left(1^{0} \& 32^{0}\right)$ \\
\hline 17 & 8.8 & 22.16 & 25 & 10 & 0.239 & 1.40 & 0.61 & $2\left(35^{0}\right.$ Bend $1 \& 60^{\circ}$ Bend 2$)$ \\
\hline 18 & 8.8 & 22.16 & 19 & 28 & 0.239 & 1.40 & 0.61 & $2\left(35^{\circ}\right.$ Bend $1 \& 60^{\circ}$ Bend 2$)$ \\
\hline 19 & 8.8 & 22.16 & 13 & 10 & 0.239 & 1.40 & 0.61 & $2\left(35^{\circ}\right.$ Bend $1 \& 60^{\circ}$ Bend 2$)$ \\
\hline 20 & 7.5 & 26.00 & 13 & 28 & 0.303 & 1.70 & 0.73 & $2\left(35^{\circ}\right.$ Bend $1 \& 60^{\circ}$ Bend 2$)$ \\
\hline 21 & 6.5 & 22.46 & 13 & 28 & 0.281 & 1.50 & 0.65 & $2\left(35^{\circ}\right.$ Bend $1 \& 60^{\circ}$ Bend 2$)$ \\
\hline 22 & 7.5 & 26.00 & 13 & 24 & 0.303 & 1.70 & 0.73 & $2\left(35^{\circ}\right.$ Bend $1 \& 60^{\circ}$ Bend 2$)$ with VEG. \\
\hline 23 & 10.5 & 18.57 & 25 & 60 & 0.183 & 1.14 & 0.50 & $2\left(35^{\circ}\right.$ Bend $1 \& 60^{\circ}$ Bend 2$)$ \\
\hline 24 & 9.5 & 20.53 & 25 & 24 & 0.213 & 1.32 & 0.57 & $2\left(35^{\circ}\right.$ Bend $1 \& 60^{\circ}$ Bend 2$)$ \\
\hline 25 & 7.5 & 26.00 & 25 & 3 & 0.303 & 1.70 & 0.73 & $2\left(35^{\circ}\right.$ Bend $1 \& 60^{\circ}$ Bend 2$)$ \\
\hline 26 & 6.5 & 22.46 & 25 & 28 & 0.281 & 1.49 & 0.65 & $2\left(35^{\circ}\right.$ Bend $1 \& 60^{\circ}$ Bend 2$)$ \\
\hline 27 & 7.5 & 26.00 & 25 & 3 & 0.303 & 1.70 & 0.73 & $2\left(35^{\circ}\right.$ Bend $1 \& 60^{\circ}$ Bend 2$)$ with VEG. \\
\hline
\end{tabular}

sand-waves attained quasi-equilibrium state after certain period, however their development in down-stream was found to be a continuous process. The magnitude and distribution of the sand waves were irregular, three-dimensional and essentially function of time. Bed forms in first bend region, where spurs located, was observed with high amplitude and long wavelength that attained quasi-equilibrium state after $15-25 \mathrm{hrs}$ resulting further development of sand waves. Large bed scour was observed in opposite inner bend in shear layer region with maximum constricted velocity, observed by Giri et $\mathrm{al}^{8)}$. One more significant observation was the inception of bed-form development in form of ripple from inner bank of successive bend, however as time went by it covered all outer bank (after 15-20 Hrs depending on flow intensity) causing deep scouring in second bend exit region for all cases with higher flow intensity (even more scouring than near spur region in Case7, 8 \& 11). The bed-form migration pattern, scouring near spurs and deposition was found to be distinctive in case of straight reach and bend entrance under similar hydraulic condition, mentioned elsewhere in detail ${ }^{9)}$.

It is of importance to note that migration of sand wave in upstream reach was observed with the migration speed of $0.3 \mathrm{~m} / \mathrm{hr}$ in couple of cases with velocity a little higher than threshold (Case 7, 8). 


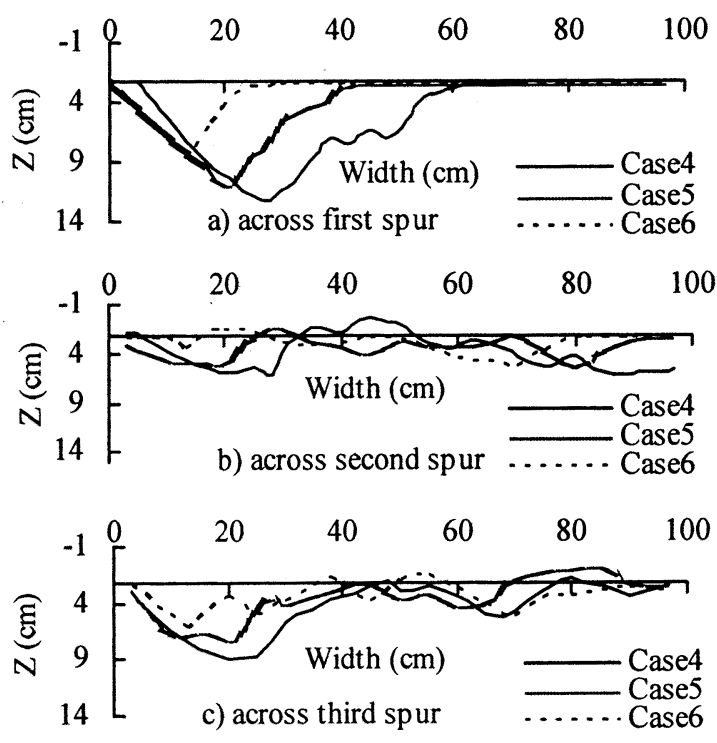

Fig. 2 Cross section profiles

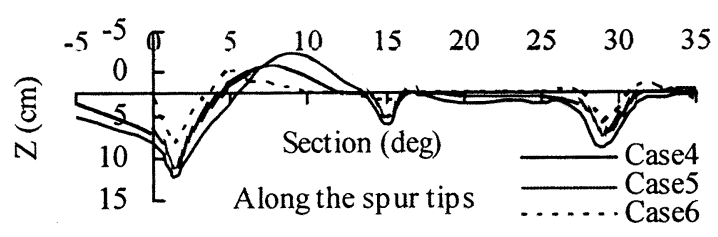

Fig.3 Longitudinal profile along spur tips

Migration pattern of these sand waves was observed using digital camera in certain intervals (1-3 hrs), which has shown some interesting features of their movement. More detail study can be found elsewhere ${ }^{9}$. Effect of spurs on opposite bank as well as bed evolution near the series of spurs has been depicted in Fig.2 \& 3. Effect of bed-forms and, in turn, changeable flow condition on development of scour in successive spur placed within the recirculation region was found to be quite significant depending upon the grain size, in other words, flow intensity in terms of grain size. A clear distinction can be observed from Fig.6. The reason of bigger scour-hole in successive spur with fine sand bed is thought to be due to the bed-form that may create complicated flow-structure near successive spur depending on flow intensity. Similarly, for $1.2 \mathrm{~mm}$ grain-size, magnitude of local scour and deposition pattern near spur placed in $35^{\circ}$ of $1^{\text {st }}$ bend and $60^{\circ}$ of $2^{\text {nd }}$ bend was found to be distinctive that can be seen in Fig.4 as an typical example. Volume of scour is 1.4 times greater whereas depth is 1.2 times deeper near spurl.

Consequently, scour-holes \& deposition pattern observed in these experiments is found to be associated with channel plan-form and allocation of spurs. For instance, in some cases, the scour did not attain equilibrium state near $2^{\text {nd }}$ or $3^{\text {rd }}$ spur despite the quasi-equilibrium state observed near $1^{\text {st }}$ spur.

Experiments with vegetation were performed with $1.2 \mathrm{~mm}$ sand bed that revealed the impact of
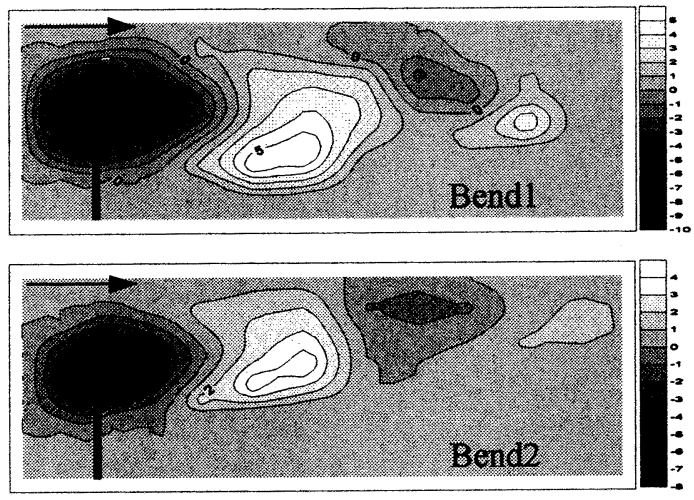

Fig.4 Bed near spurs (Case23, half width of channel)

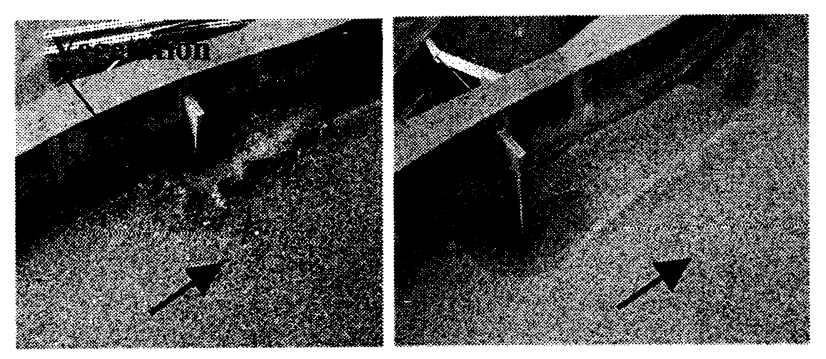

Photo1 Scour \& deposition pattern near spur with \& without vegetation (loose vegetation)
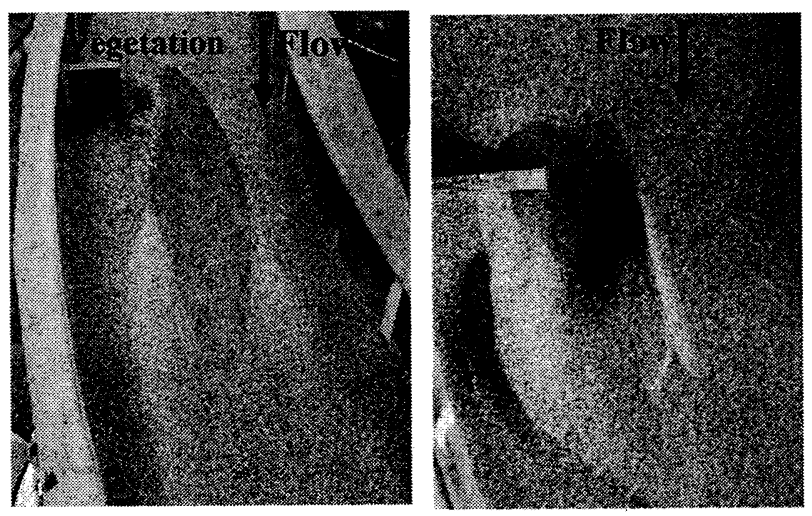

Photo2 Scouring near spurs with \& without vegetation

(Case $25 \& 27$, dense vegetation)

vegetation, not only in form of turbulence dissipater but strength of root as well. It is found that vegetation has significant impact on scouring and deposition pattern (Photo1). However, for Case27, scour is seen to occur in region away from spur, particularly in Bend 2. The depth of bed scour after $3 \mathrm{hrs}$ in the region away from vegetation near spur 1 \& spur 2 was $4 \mathrm{~cm} \& 12 \mathrm{~cm}$ respectively, whereas scour depth in the vicinity of spur1 \& spur 2 without vegetation was $13.2 \mathrm{~cm} \& 12 \mathrm{~cm}$ respectively (Photo2). The reason of bed degradation near spur2 is thought to be the constriction effect that is influenced by vegetation, in particular root strength along with the configuration of bend as well.

Determination of temporal variation of local bed 
a)

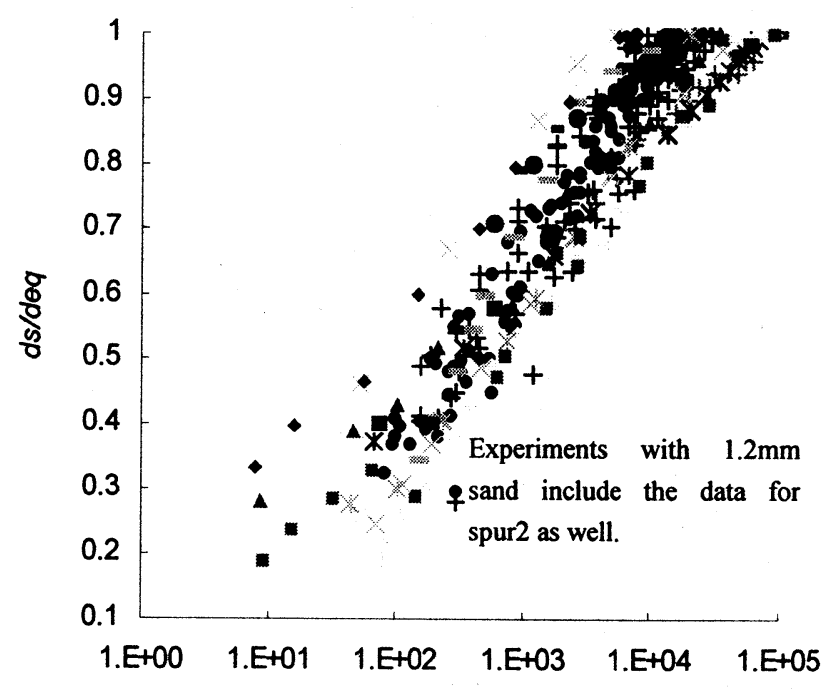

Strouhal number (Sh)
- Author- 9 experiments $w$ ith $0.28 \mathrm{~mm}$ sand

+ Author- 11 experiments $w$ ith $1.2 \mathrm{~mm}$ sand Gilt $5 \exp , d=0.9 \mathrm{~mm}, \mathrm{~L}=204 \mathrm{~mm}, \mathrm{~h}=36 \mathrm{~mm}-54 \mathrm{~mm}$ * Gill 3 exp, $d=1.52 \mathrm{~mm}, \mathrm{~L}=204 \mathrm{~mm}, \mathrm{~h}=36 \mathrm{~mm}-52 \mathrm{~mm}$

- Ahmad- $d=0.25 \mathrm{~mm}, \mathrm{~L}=152 \mathrm{~mm}, \mathrm{~h}=61 \mathrm{~mm}$

+ Ahmad- $d=0.25 \mathrm{~mm}, \mathrm{~L}=457 \mathrm{~mm}, \mathrm{~h}=183 \mathrm{~mm}$

- Ramu- $d=10.5 \mathrm{~mm}, \mathrm{~L}=300 \mathrm{~mm}, \mathrm{~h}=74 \mathrm{~mm}$

Cardoso- $d=0.835 \mathrm{~mm}, \mathrm{~L}=270 \mathrm{~mm}, \mathrm{~h}=78 \mathrm{~mm}$

Cardoso- $d=0.835 \mathrm{~mm}, L=800 \mathrm{~mm}, \mathrm{~h}=55 \mathrm{~mm}$

- $K w$ an- $d=0.85 \mathrm{~mm}, L=164 \mathrm{~mm}, h=100 \mathrm{~mm}$

- $K w$ an $-d=0.85 \mathrm{~mm}, \mathrm{~L}=717 \mathrm{~mm}, \mathrm{~h}=50 \mathrm{~mm}$

$K w$ an $-d=0.85 \mathrm{~mm}, L=164 \mathrm{~mm}, h=50 \mathrm{~mm}$

* $K w$ an $-d=0.85 \mathrm{~mm}, L=314 \mathrm{~mm}, \mathrm{~h}=50 \mathrm{~mm}$

1. Etema- $d=1.9 \mathrm{~mm}$, Dpier $=101.6 \mathrm{~mm}, \mathrm{~h}=300 \mathrm{~mm}$

- Etema- $d=0.38 \mathrm{~mm}$, Dpier $=101.6 \mathrm{~mm}, \mathrm{~h}=300 \mathrm{~mm}$

- Etema- $d=0.84 \mathrm{~mm}$, Dpier $=150 \mathrm{~mm}, \mathrm{~h}=600 \mathrm{~mm}$

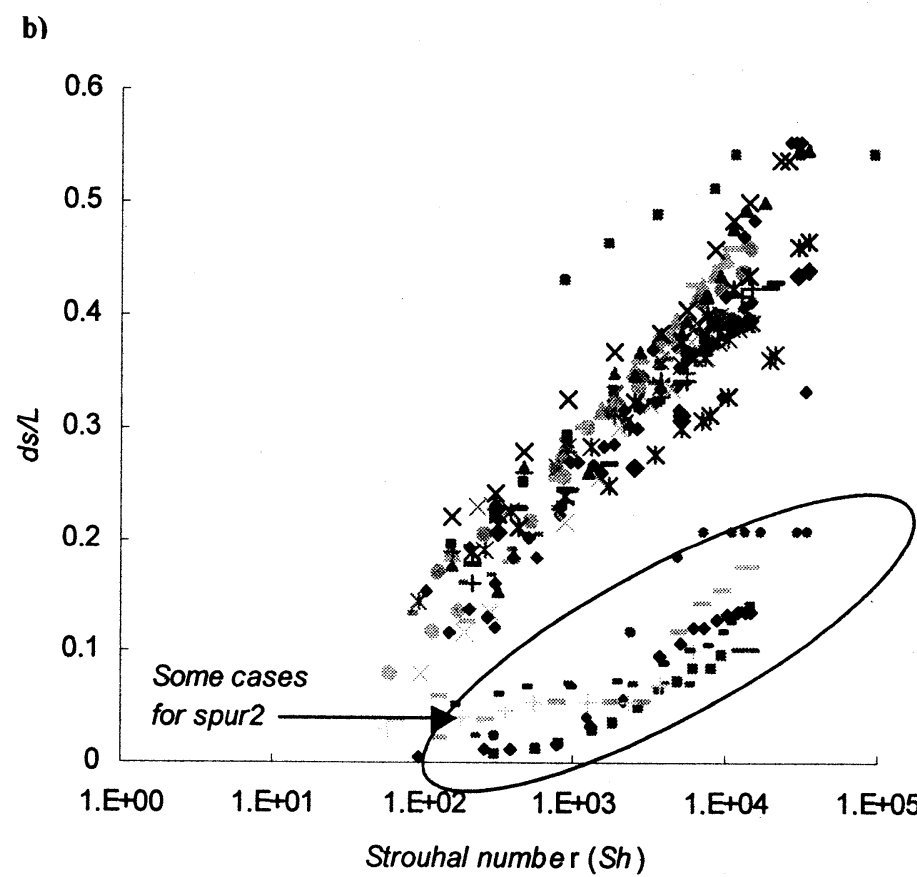

Case1

- Case2

- Case3-spur2

* Case4

- Case4-spur2

Case5

- Case5-spur2

+ Case6

- Case6-spur2

Case10-spur2

- Case12

Case12-spur2

Case13-spur2

Case14-spur2

- Case15

- Case15-spur2

- Case17

+ Case17-spur2

$\times$ Case18

$\times$ Case19

- Case20-spur2

- Case21

- Case21-spur2

* Case24-spur2

- Case24

- Case26-spur2

* Case26

- Cardoso

c)

- Ramu

\begin{tabular}{|l|}
\hline Data range for Fig.5a: \\
\hline$U_{d} / U_{t}=0.51-1.07$ \\
$L / h=1.3-14.3$ \\
$L / B=0.07-0.5$ \\
$d=0.25-10.5 \mathrm{~mm}$ \\
Where, \\
$U_{0}$ - Approach velocity; \\
$U_{t}$ - Threshold velocity; \\
$L$ - Length of structure; \\
$h$ - Flow depth; \\
$B$ - Channel width; \\
$d$ - Sediment diameter. \\
\hline
\end{tabular}

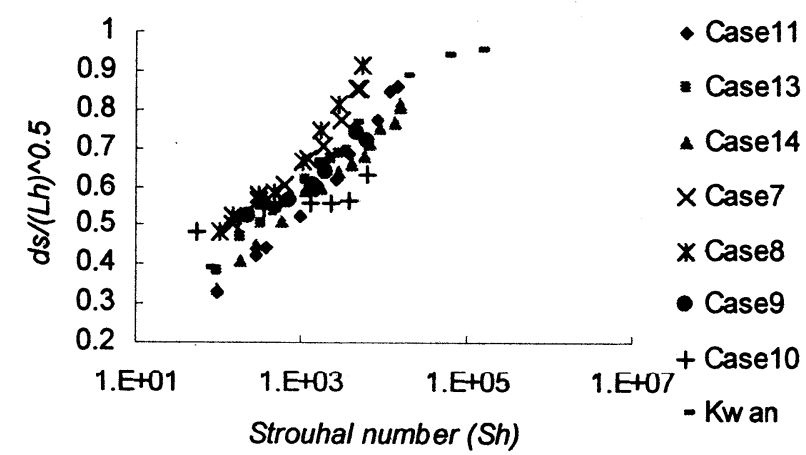

Fig.5 Temporal development of local bed evolution

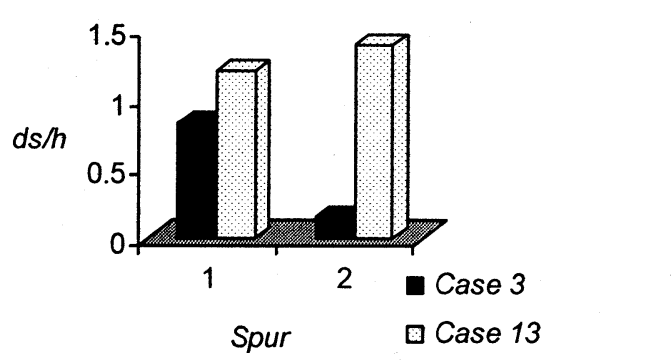

Fig.6 Comparison of scour depth for cases with similar hydraulic condition 
evolution is of importance in order to define the scour development pattern according as the time. Some studies ${ }^{10}$ were performed in the past to evaluate temporal development of relative scour depth near bridge pier and abutment. In this study, temporal development of scour-holes near series of spurs with different allocation was observed. A general trend was developed for temporal variation of relative scour-depth using modified Strouhal number. Other significant experimental data was used for verification. It has been explained heretofore that the depth and volume of scour hole seems to depend on various factors, however it was found that temporal development pattern can be generalized. For this purpose, a criterial relationship has been used in terms of relative scour depth as a function of modified Strouhal number as:

$$
\frac{d_{s T}}{d_{s e q}}=f(S h)
$$

$S h=\frac{U_{0^{*}} \times T}{h}$

where, $S h$ - Strouhal number; $d_{s T}$-Scour-depth at $T$; $d_{e q}$-Quasi-equilibrium scour-depth; $T$ - Time; $U_{0^{*}}$ Particle shear velocity, $h$ - Approach flow depth.

The result has been verified using significant experimental data set from 20 experiments obtained independently by other researchers for the case of abutment ${ }^{11)}{ }^{12}$, , spur dike ${ }^{2), 3)} \&$ even bridge pier ${ }^{13)}$. These experiments were conducted for wide range of time \& other variables. Besides, in authors' study (20 experiments), scour development pattern was observed near spurs, placed in different bend simultaneously. As can be seen from Fig.5 (a), all data points are found to be considerably well fitted despite wide range of variables. Preliminarily, following best fit expression can be adopted to determine time development of relative scour depth:

$\frac{d_{s T}}{d_{e q}}=0.108 \times \operatorname{Ln}(S h)-0.068$

where, $S h$-Strouhal no.; $d_{s T}$ Scour-depth at time $T$; $d_{e q}$-Quasi-equilibrium scour-depth.

From (3.9), $S h$ corresponding to equilibrium state can be defined, namely about 20000 . Similarly, time development of relative scour-hole in comparison with equilibrium state can be determined using (3.8) \& (3.9). Further work is necessary to define the quasi-equilibrium scour depth so as to quantify the absolute scour depths. Some preliminary results of scour development have been depicted in Fig.5 (b \& c). It can be seen that for the case with higher flow intensity, the parameter $d s / \sqrt{L h}$ gives better correlation whereas for the case with lower flow intensity as well as cases with spurs in second bend, $d_{S} / L$ shows better correlation with Strouhal number. However, correlation was seen not so well for the case with very low flow intensity $\left(U_{d} / U_{t}<0.6\right)$.

\section{WRAP UP}

Temporal variation of relative local bed evolution is found to be well-defined in terms of modified Strouhal number. Time factor approach derived herein can be used in combination with formulae for equilibrium scour depth for spurs and pier like structures. Further study is necessary to identify more precise value of $S h$ for auto-model region. Experimental evidences have revealed significance of spurs allocation, bend effect \& vegetation on local bed evolution. Consequently, the evaluation of absolute value of quasi-equilibrium scour-depth is supposed to be done, since it alters according as allocation, bend and vegetation impacts that do not appear to be considered in previous studies.

\section{REFERENCES}

1) Shimizu, Y. \& Nishimoto N.: Numerical analysis of bed variation around spur dikes. Research report of CERI of Hokkaido Development Bureau, 1993.

2) Ahmad M.: Experiments on design \& behavior of spur dikes. Proceedings, Minnesota Int. Hyd. Con., Minneapolis, Minn, 1953.

3) Gill M.A.: Erosion of sand bed around spur dikes. Proceedings of ASCE, Vol.98, 1972.

4) Kuhnle et al.: Local scour associated with angled spur dikes. ASCE, Journal of Hydraulic Engineering, Vol.128, No.12, 2002.

5) Begin Z.B.: Curvature ratio and rate of river bend migration-update, ASCE, Journal of Hydraulic Engineering, Vol.112, No.10, 1986.

6) Mikhalyov M.A.: On criterial condition of incipient motion of non-cohesive sand particle from bed \& bank (in Russian). Izvestiya VNIIG, Vol.126, 1980.

7) Knoroz V.S.: Non-eroding velocity \& determining factors for non-cohesive sand (in Russian). Izvestiya VNIIG, Vol.59, 1958.

8) Giri et al.: Flow characteristics in a mildly meandering channel with \& without river training structures, Annual Journal of Hydraulic Engineering, JSCE, Vol.47, 2003.

9) Giri, S. \& Shimizu Y.: Structure-induced bed forms and temporal development of local bed evolution in the bend reach of a laboratory flume. $3^{\text {rd }}$ IAHR Symposium on RCEM, Barcelona 2003.

10) Melville, B.W. \& Chiew Y.M: Time scale for local scour at bridge piers. Journal of Hydraulic Engineering, Vol.114 (10), 1999.

11) Kothyari U.C. \& Rangaraju K.G.: Scour around spur dikes and bridge abutments. Journal of Hydraulic Research, IAHR, Vol.39, No.4, 2001..

12) Cardoso A.H. \& Bettess R. E.: Effect of time \& channel geometry on scour at bridge abutments. Journal of Hydraulic Engineering, ASCE, Vol.125, No.4, 1999.

13) Ettema R.: Scour at bridge piers. Rep. No.216, School of Engineering, University of Auckland, New Zealand, 1980.

(Received September 30, 2003) 